\title{
Teaching Grammar with the Help of Computer- Based Puzzles and Incessive Reflectiveness Development in a Vocational School Setting
}

\author{
Horváth Balázs Zsigmond ${ }^{1 *}$, Imre Soltész ${ }^{2}$, Bence Blaske ${ }^{3}$, Orsolya Horváth ${ }^{1}$, Anita Szabó ${ }^{4}$ and \\ Botond Csorba ${ }^{1}$ \\ ${ }^{1}$ Pogány Frigyes Vocational Secondary School, 11 Thököly út, 1183 Budapest, Hungary \\ ${ }^{2}$ Hungarian Origami Circle, 71 Szigeti utca. 7633 Pécs, Hungary \\ ${ }^{3}$ SAP Hungary, 7 Záhony utca, 1031 Budapest, Hungary \\ ${ }^{4}$ Cognizant Hungary, 40-44 Hungária körút. 1087 Budapest, Hungary
}

Received: December 12, 2017; Accepted: December 30, 2017; Published: January 08, 2018

*Corresponding author: Horváth Balázs Zsigmond, Pogány Frigyes Vocational Secondary School, 11 Thököly út, 1183 Budapest, Hungary, Email: zsmondi@gmail.com

\begin{abstract}
This article represents the findings about the usefulness of computer-based puzzles and grammar teaching with the help of specially-compiled task sheets for sentence formation. The combination of these methods may add a unique approach to the curricula when it comes to the teaching of tenses. The students learn and think about the formation of these tenses gradually and then use their acquired knowledge on their own. Using the benefits of 21st century technology it is vital to add a more humanistic approach to seemingly dry language materials for the benefit of the youngest generations who are bombarded with cell-phone games and have a limited attention span.
\end{abstract}

Keywords: Computer-based puzzles; Computer-assisted language learning; Sentence formation; Tenses;

\section{Introduction}

The aim of this article is to explore what kind of computerbased puzzles are really useful in the 21st century for teaching foreign languages and the ways to use them. What are the best ways of applying tasks requiring procedural knowledge in language pedagogy and how both visual and logical puzzles, as activities requiring that particular kind of knowledge, can be used for teaching vocabulary and grammar? A secondary aim is to discover what approaches can be used to make those aspects of English lessons more colourful that traditionally require frontal teaching. We will try to explore how different definitions of procedural knowledge can be applied in learning processes and what memory-related issues must be considered using activities. Is it possible to gain new insights in connection with the mechanics of how puzzles help learners in achieving their goals?

In pedagogy, representational knowledge is increasingly replaced by the notion of teaching competencies about how to solve different problems. (Dietrich A, [1]) Puzzle solving builds on procedures (Ji-Sook Han, [2]), especially instructional puzzles (Adedoja GO, [3]) and so it would be beneficial to see whether the literature has anything to offer in connection with these concepts. Procedural knowledge can also be linked to mathematics in the way different formulas are combined for application (Wes, 2011) and computer sciences, and so it is fitting to explore if there are any links to justify using puzzles in task-based language classes. We may arrive to this thought, because the basics of applying language rules also can be described as mathematical rules with the help of transformational grammar (Peters, et al. [4]).

\section{Literature Review}

As we will see on the following pages, the referenced definitions will agree on that procedural knowledge is about knowing how to do something. That is why it is sometimes put into opposition with declarative knowledge yet the two are interdependent and are parts of a larger category called problem-solving knowledge. As general problem-solving skills are valuable in any learning process and to overcome the above mentioned opposition, the information-processing theory was established declaring that the role of factors such as working memory capacity, organization of long term memory, and cognitive retrieval of relevant information are equally important (Hardin, [5]).

Declarative knowledge and procedural knowledge can turn into each other and thus grammatical competence can be achieved. This suggests that grammatical and communicative competences are linked and any new information first becomes in the learner's mind declarative knowledge and serves as building blocks for further production - paying active attention is the key to developing methods in the mind that can be used later (Anderson JR, [6]). 


\section{Tasks that are based on procedural knowledge}

There is a link between visual tasks, such as jigsaw puzzles and memory (Samida DK, [7]). Memory strategies can be formed with simple procedural principles like laying things out in order, making associations, and reviewing information from the mind. The principles are employed when a learner confronts a challenging situation when learning vocabulary or grammar - this can be pronunciation, spelling, remembering the word or word order. In the case of procedural memory, an image of the words in question could be used as jigsaw puzzles.

As the learners advance to higher levels of proficiency, memory strategies are used in an ever decreasing frequency. Use does not vanish totally, but awareness of using the helping strategies becomes less. Knowing a word involves both knowing what it means and knowing in which contexts it can be used. Specialist vocabulary items present a special case as they are needed in specific fields and so are less demanding to learn. English is full of words that have different meanings with the same spelling and pronunciation (Samida DK, [7]).

The above mentioned view is suitable for pedagogical reasoning; picture puzzles could be used to teach specialized meanings of words that fall into the common or specialized categories for better memorisation. The declarative and procedural aspects of lexical competence demand that the learner should concentrate on groups of words with specific and general meanings. Declarative knowledge is responsible for knowing the list of the words and procedural knowledge for using them in the right context.

\section{Different aspects of tasks for consideration}

The tasks should make it easier for the learners to remember harder expressions with specific meanings or with specific spelling or pronunciation without 'atomization' meaning to isolate word items from contexts. To avoid atomization we must consider different culture-related teaching approaches. Although this is a cultural aspect, it is necessary to pull it into this topic since the application of puzzles must be clarified after dealing with the definitions of different knowledge types and carrying out any research depends on the acceptance of the learners.

Post-method pedagogy should be applied based on three parameters, which are particularity, practicality, and possibility. Particularity is the notion that every language teaching program must be aimed at the goals of the learners within a particular institutional context in the particular sociocultural 'milieu'.

Practicality is the relationship of theory and practice without clashes between the two. It depends on the local knowledge and theory of practice of the educators. Possibility is simply the factor that measures how feasible the methods are with which the educators present their materials to the learners.

It is also important that communicative language teaching must prepare language learners for the real world with activities so there would be life-like situations and thinking must be enhanced by puzzles not mattering what kind they are (Alemi M, et al. [8]).

\section{Clarifying and justifying the use of puzzles in the classroom}

Puzzle solving is mainly concentrating on crosswords and usual exercises like gap filling and cloze tests, etc. It is hard to find true scientific publications beyond them, because the leading piece of reference literature is Marcel Danesi's book Puzzles in Language Teaching dating back to 1979 . The main argument behind using puzzles in the classroom to stimulate creative thinking and to avoid boredom caused by solving only monotone tasks, yet it seems that what can be accessed from the literature, lack outside of the box thinking concerning creativity and studies like Loza Tavassoli's on-line publication even points out that there seems to be no significant difference between puzzle-solvers and simple text translators concerning how well or fast they can learn new expressions (Danesi M, [9]).

In contrast, the study conducted by Amel Bouteliaten from the Mentouri University-Constantine provides strong evidence concerning the usefulness of puzzles in the classroom. The author of the research aimed to investigate the effectiveness of using crossword puzzles as a teaching technique to enhance the vocabulary knowledge of freshman English students.

The role of the teacher becomes merely that of a guide when solving puzzles in the classroom, and the exercises become increasingly more learner-centred and that is the key point. The approach is focused to help learners develop a deeper knowledge of the lexicon by building on their use of logic and urge them to use this logic to put learnt expressions in context and use them effectively. If students learn vocabulary with the help of crosswords, their level of accomplishment in writing in terms of lexical usage, spelling will increase (Bouteliaten A, [10]).

There are ways of incorporating logic puzzles, such as matching as a task-based teaching technique in foreign language classrooms. Logic puzzles stimulate the mind in a joyful way and also produce pedagogical benefits which are believed to include an increased exposure to vocabulary presented in specific contexts with a distinct focus on comprehending meaning, a heightened mental engagement with the key vocabulary at a deep level of processing, and the fostering of inference skills and the ability to guess meaning from context, all in a relatively brief amount of class time. Logic puzzles offer a great deal of adaptability in exactly how they are utilized in class. Ultimately, it can be concluded that logic puzzles should be explored more thoroughly for their potential benefits to classroom teaching and the learning of foreign languages through continued use and more substantial research studies (McDonald K, [11]).

The puzzle-types could the present the reader with the objective of matching items with each other base on logic. Given a scenario, clues, and a general familiarity with the items should be enough to deduce the solution. - Here again jigsaws could be considered as clues-providing a bottom-up logical approach. The whole collection of clues serve as a deductive tool further enhancing the use of mental capacities. 
Logic puzzles may serve the need to put vocabulary items into context, although their application is not revolutionary in teaching. Language learners can make rational guesses about the meanings of unknown words and thereby they can possibly enhance the chances of acquiring a strong and stable vocabulary with the help of logical puzzles. Further in-depth studies are needed to prove a consistent positive effect beyond making the classes more interesting (McDonald K, [11]).

María Rosario Cuesta from the University of London published an article which matches different aspects of task-based language teaching with top-down and bottom-up methods. The author gives clear definitions of these and states that although course book writers mainly concentrate on bottom-up syllabuses and neglect top-down approaches, which should be in the focus of applying communicative competence, special circumstances within a classroom should not allow a clear distinction between the two. Competent language users will in time indeed acquire top-down ideas about their communicative strategies, yet a good balance and awareness of bottom-up pedagogy is needed (Cuesta MR, [12]).

Bottom-up processing is mainly data-driven as it builds up systems from basic pieces of information and the only problem is that vocabulary learning is sometimes too dry in representation - it focuses mainly on formal language, but there may be many circumstantial reasons for that and one must not forget that the pressure of time teachers face in order not to have any language learner unattended during the learning process. As a critical point of view, we could establish based on findings that the safest approach to a well-established teaching system is to balance out different notions and fit them to the need of the groups that actually sit inside the classrooms - as it was in the case defining knowledge types, there is still a debate going on.

\section{The presentation of puzzles and the current technology trend}

After all the discussion we can finally arrive to the topic of applying puzzles in teaching in the 21st century. With technology shaping our lives, the use of computers also appeared in language teaching slowly but surely. The question arises, how should puzzles look like on the computer in order for the language learners to use them beneficially? Screen elements, such as the menus from which the participants choose their options must get rid of distracting items and those options that are not available at any given time of solving the puzzles should not be visible. They don't serve as further assistance to the puzzle solvers because test subjects could identify almost immediately how the puzzles could be solved. This issue comes into the limelight, because the wide-spread operating systems of our times always show greyedout items in their menu arrangements and this characteristic comes with the programming language they were written in. Arrangements with all items visible is much more easier to code, but we must not forget that basic operating system programs are not meant to be educational, but to be easy to understand through elements that could be expected to appear always at the same place. The above mentioned screen arrangement without unnecessary items encourages procedural knowledge use from the students, but it is only successful if users confront the interfaces many times and they can practice it (Von Nimwegen C, et al. [13]).

There are many sites on the Internet offering puzzles for every level, but for actual use it is better to first measure what the problems of the students are and then search for suitable puzzles, rather than choosing something interesting randomly in order just to increase interest or intrinsic motivation. Of course teachers who are not accustomed to programming may have no other choice, but the introduction of puzzles must be a careful approach in the long run.

There are more puzzles focusing on words rather than sentences and in their nature, there are further two main categories of these sites. The first type offers puzzle generators and the results can be downloading in printable document format for classroom distribution. Others offer on-line services and their quality varies. In this article we will only mention a handful of these sites, focusing on some influential examples.

Looking back in history, the earliest somewhat computeraided game tool was Speak and Spell designed in 1978. It helped teaching spelling using a predictive coding speech synthesizer linked with a visual display. It is so popular that it has a modernday emulator available on-line at: http://www.speaknspell. co.uk/.

Another pioneer product designed in 1983 is Reader Rabbit which has become a franchise and is very applicable and can stand as an example to follow. It is built around the A.D.A.P.T. Learning Technology idea (Assessing abilities, Developing skills, Adjusting levels, Providing help, and Tracking progress) especially tailored for computer-using students.

The following titles focus on words and their formation and are puzzle generators both of them are easy to use:

- Crossword puzzle maker (https://worksheets. theteacherscorner.net/make-your-own/crossword/)

- Instant Online Crossword Puzzle Maker (https://www.puzzlemaker.com/CW/ )

The next titles are on-line puzzles:

-The American Association of Retired Persons (AARP) runs a site offering different usable and good-quality on-line games with the main goal of entertainment (http://games.aarp.org/ category/word).

-Boatload Puzzles presents a simpler and more traditional approach and uses less multimedia elements (https://www. boatloadpuzzles.com/playcrossword).

- Mind Games is similar in execution to the AARP site

(https://www.mindgames.com/Word+Games).

The last titles are on-line puzzles focusing on sentence formation: 
-Sentence Monkey focuses on different phrases and structures with the method of gap filling: https://www.eslgamesplus.com/ sentence-monkey/

-Primary Games is a good idea but the site loads slow and the screen elements may somewhat hinder concentration

(http: / / w w w.primarygames.com / langarts / simplesentences/)

-Turtle Diary unfortunately needs membership.

(https://www.turtlediary.com/game/sentence-unscramblefourth-grade.html)

\section{Piloting}

Nowadays, it is a well-known deficit in language teaching that students get confused even from the beginning when they have to acquire the exact uses and structures of tenses and linguistic expressions without having the necessary time-span to learn and practice them step by step. They cannot separate them or notice the difference in situations when the chosen tenses are required. This problem affects not only on the beginner learners, but on the experienced students as well who have to take the schoolleaving exam (both written and oral) to finish their secondary school education. The students have the fear of not knowing what to answer after an introduction or greeting in a conversation as it progresses.

The most problematic issue is that the students not only waste points of their final exam, if the students get this kind of impulsion during the whole period during secondary school, they could believe learning languages is just a big stalemate for them. They cannot see and understand the sorted build-up of the grammatical rules. Accordingly, they will assume the problem arises because of their own personal properties, and thus they are not able to understand languages.

This could be followed by grave consequences shown in the percentage rate of how many people know at least one foreign language between the ages of 25 and 64. This data was revealed in 2017 by the European Comission, and it shows that seven countries cannot reach even $60 \%$, two of them, including Hungary, are under 40\% (McCarthy N, [14]).

We can find extraordinarily problems in the Far East as well, even in the developed countries, especially in Japan. Because of test-based education and the low quality of coursebooks, students memorize the rules, but just on the lexical side. Building up a grammatically correct sentence on their own, spontaneously is a pretty slow and complicated process, and at this point they are tremendously far from a full, correct and fluent conversation. (Japan Today, [15])

In order to attend to this obstacle, the average students need to get logically sorted, serried and progressively more and more difficult, but evenly so transparent tasks. That is why we started developing the LGATE-pages (Lépcsőzetes Gondolkodást Alapozó és Tanulást Elősegítő lapok - Incessive ReflectivenessDevelopment and Learning-Assistance pages). These contain the most important issues that are missing from the casual course of study of the modern education system.

It doesn't matter if it is about tenses, linguistic expressions, we observed that students need to acquire and memorize the rules and know about the most common mistakes most of us would make initially, both as a beginner and as a well-experienced person - the process is gradual and thorough.

One year ago we began to start a catch-up course for twelve students preparing for the school-leaving exam. During that time the students expressed the need to revise all the necessary tenses from the start. Since time was short, it was advisable that we combine translation exercises with tense practice in order to achieve a higher score in the composition, letter writing part of the exam. This was done by devising a series of the prototypes of the LGATE task sheets, each consisting of 40 translation exercises with basic sentences to English from the mother tongue. The sentences were both in the declarative and denying forms and also as questions. With time the pages got more and more difficult and harder to make. As the students progressed they could simultaneously learn the rules, develop their skills and make note of their weaknesses. At the very end of the pilot study, the most problematic sentence patterns were analysed after being read out by TTS (text-to-speech) voices also used in dialogue simulations (Horváth BZ, [16]).

After the period of 12 weeks, the final result was between $36 \%$ and $74 \%$. At the final exam the students performed $10 \%$ better overall and $75 \%$ of them did their composition without mistakes. After this positive experience we came to the conclusion that similar activities should be introduced in the next freshman year in a class as trial, but targeting a younger age group with the help of supplementary computer-based puzzles. This was a vital issue as the freshman students need to adopt and find intrinsic motivation and simple drilling-like tasks would make them reluctant towards the subject. The key issue is that the LGATE pages with the extension of practice with computer-based puzzles in order to raise interest show promising results. For an example of tasks, see Figure 1.

\section{Current Research outline}

The aim of this research to develop a long term practice for vocational school students to overcome simple grammar issues in cases of interaction and simple composition writing and/ or translation. To achieve this we are continuously looking at different puzzle types, realisation techniques using TTS (text-tospeech) voices and grammar practising methods with the abovementioned LGATE task sheets. The voices provide the possibility of endlessly extending the puzzles.

Teachers cannot compete with the gaming media articles on the level of interest rising. Educational games are to be developed that are fast to solve with minimal effort. Sometimes minimalist games are the best to trigger thinking. The children's gaming habits were observed and our realisation was adjusted to them. The main goal is to turn declarative knowledge into procedural knowledge and use them both for learner development. To use the 


\section{1. Én csaltam. \\ 2. Te csaltál. \\ 3. Ö csalt.(f) \\ 4. Ö csalt.(n) \\ 5. Mi csaltunk}

1. Én eladtam a házat.

2. Te eladtad a házat.

3. Ö eladta a házat.(f)

4. Mi eladtuk a házat.

5. Ök eladták a házat.
1. Te futottál?

2. Ö futott?(f)

3. Ö futott?(n)

4. Ök futottak?

5. Mi futottunk?
1. Én nem viseltem sálat.

2. Ő nem viselt sálat.(f)

3. Ök nem viseltek sálat

4. Te nem viseltél sálat.

5. Ö nem viselt sálat .(n)

Translation task

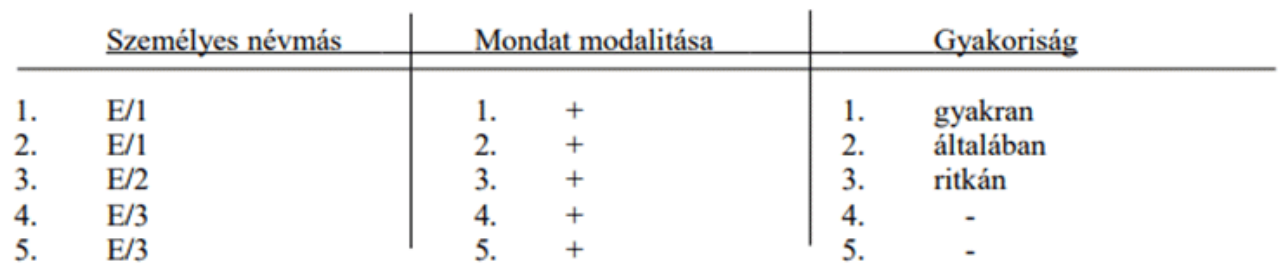

Writing task

Figure 1:Some sample LGATE tasks

previous knowledge of the students from the puzzles to formulate correct sentences. Practice shows that in this case we are looking more into different puzzle types than crossword puzzles - which are an all-time favourite, but may get boring after a while. The work needs to fit into the theoretical framework of fast learning for the 'Z generation' and needs to tie down attention just enough to be useful. The visualization, the animation and the sound effects help students to have fun. It is also vital to mention that in the target group of 22, seven students have proven attention deficiency and are attending consultations and many of them lack the right definitions of grammar word classes even in their mother tongue. That is why TTS voices were also implemented in order to have the solutions also be heard, rather than just a visual input.

It became clear that students either like to solve word-finding games or games practising sentence structure. So far 115 students from five different classes, including the control group, tried out the puzzles. If they were presented a choice about what to study, surprisingly they have chosen to look into sentence formations more seriously, as shown in Figure 2.

This observation was final after showing the children eleven types of puzzles, including various matching exercises. The trial versions can be accessed from the following link: http:// meltingpot.hu/englishgames/ and http://solteszimre.hu/ games/bubble_popper/. The layout of the web page can be seen in Figure 3.

After practising the children are asked to fill in LGATE tests. A great deal of patients is needed from the teacher and the students as well, and the practising phase must not be interrupted or neglected.

Three methods for practising sentence patterns have emerged

Bobble popping: words of a sentence are moving across on the screen in bobbles which the player needs to pop and have the words fall down in a specific order - see Figure 4.

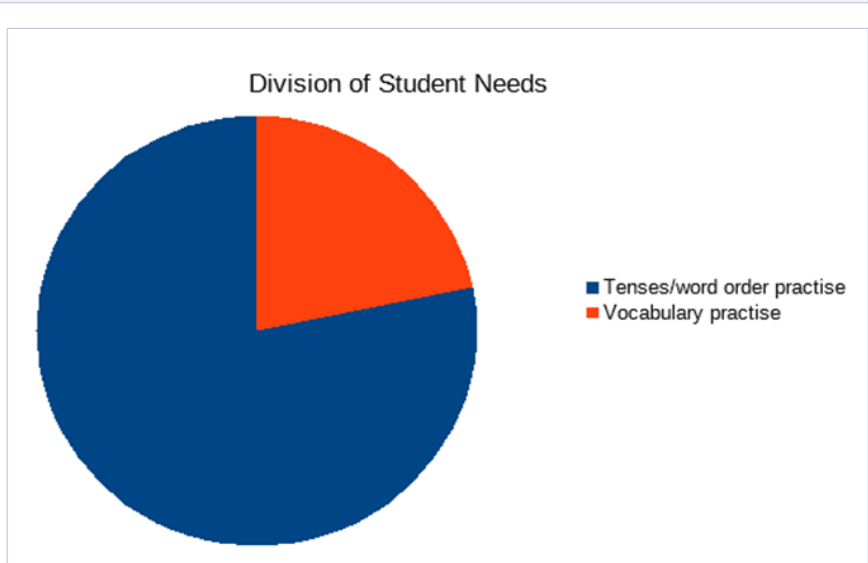

Figure 2: Out of 115 students who have tried out the puzzles, 90 thought that they are best used for studying sentence formations.

If students know the solution they still have to be precise when aiming the target as the bubbles are moving and if they are not quick enough they may miss the target and have to try again - an aspect that makes people feel that they are actually playing a game. If students miss the target by accident or find later that they put a word in the incorrect space they always have the ability to correct themselves as they can drop a new word in place of an old one and bring the old word back to the game. This puzzle shows examples of a maximum of eight word sentences so far - as at least that many words are needed to practice enough examples for present perfect sentences.

If students put a word in the incorrect place they can notice their mistake by looking at the display at the top of the screen indicating how many words are at the correct place without specifying which words exactly these are. Students who feel confident and want extra challenge may choose to play a timed game as well. The puzzles are also aimed to be arcade games as well to require a bit of dexterity.

The bubble popper game may even be more fun to play on touch screen devices as tapping on a bubble instead of using the 


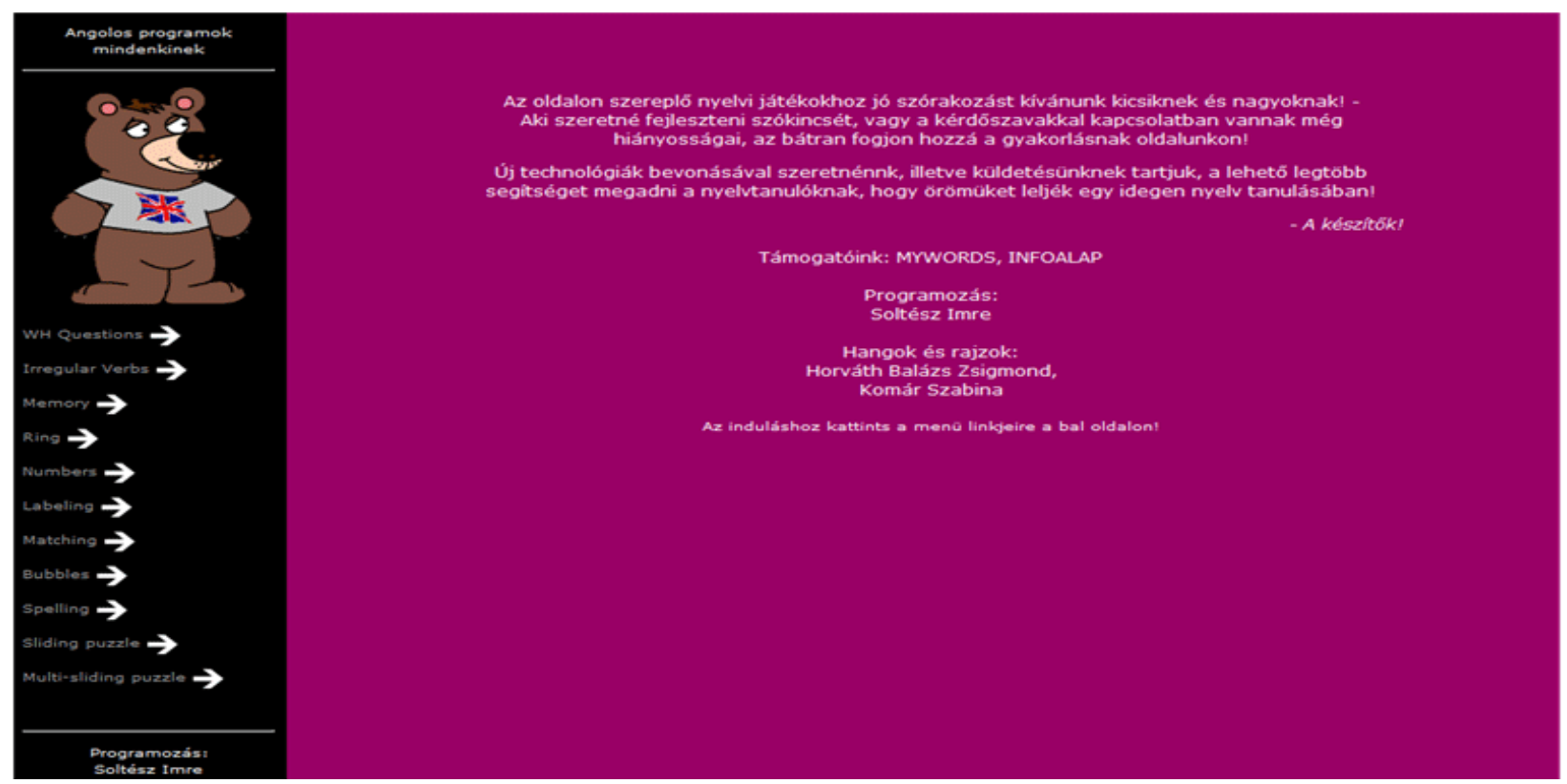

Figure 3: Layout of the web page from where the puzzles can be accessed.

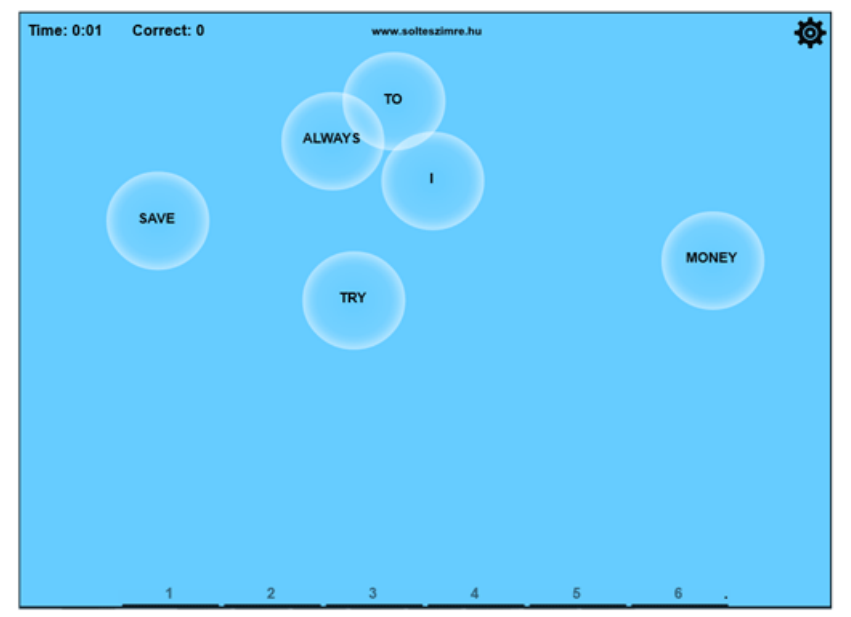

Figure 4: Layout of the Bobble popping game

cursor makes targeting easier. It is very important that the games also work on mobile devices and that the pages are responsive as children of our modern age all have such devices in their pockets.

Word snake (in the testing phase): a snake needs to be assembled from body parts represented by similar shapes with the words of the sentences on them - see Figure 5.

Slot machine/one-armed bandit (in the testing phase): a slot machine shows the randomized words of a sentence and the student has to decide whether the order of the words are correct or not. (Within the limit of four permutations the students has to encounter the right sentence pattern which he or she has to recognise). - see Figure 6.

So far only constructive criticism came back but only on minor issues: dexterity forced students to concentrate on puzzle-solving speed as well in case of the bubble-popper game and students expressed the need to be shown why the incorrect solutions were wrong. The activities received positive feedback as all of the games were thought to support language learning. From the bunch of games, matching exercises were the most popular and sentence pattern games were the most useful - that is why they were used for further development. A sample matching game is shown in Figure 7.

Altogether 215 tests took place and $64 \%$ of all students managed them with flying colours even for the first try - see Figure 8. Even the worst student managed to solve the puzzles with the least errors on the 5 th try.

\section{Methods}

Two classes from the same age group (between 15-16) were involved with the study. From the trial group of 22, 19 students took part in all the testing procedures. The control group consisted of 13 students. The groups were selected based on whether they studied the verb tenses from the devised course materials with the help of computer-based puzzles, or simply using regular coursebooks and materials. During preparation the students had access to the puzzles for practice all the time and could give feedback.

During the period of three months the trial group filled out seven specially devised tests of the practice material which three were graded as milestones for this study, but the students were aware of their progress each time. The sheets contained both translation-type and sentence composition elements. The tests were taken during regular lessons with the students separated from each other. The first three tests were based on the topic of Present Simple, and then the second three tests were based on 

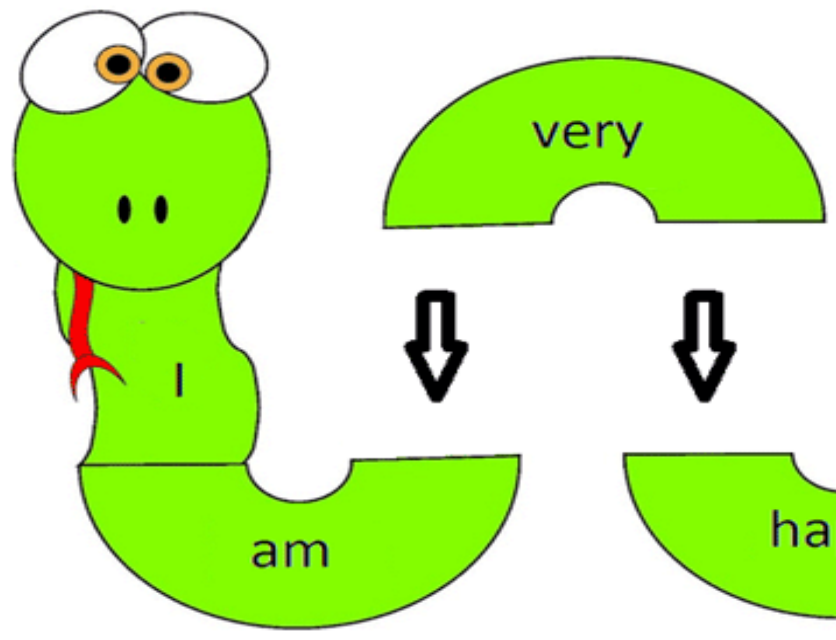

The sections of the snake are drawn identically.

Figure 5: Layout of the Word snake game

\section{1 love \\ to \\ drink wine}

The words have to be at their correct places within 4 pulls of the bandit. - The user has to decide if their order is correct.

THE WORD JACKPOT

Figure 6: Layout of the Slot machine/one-armed bandit game
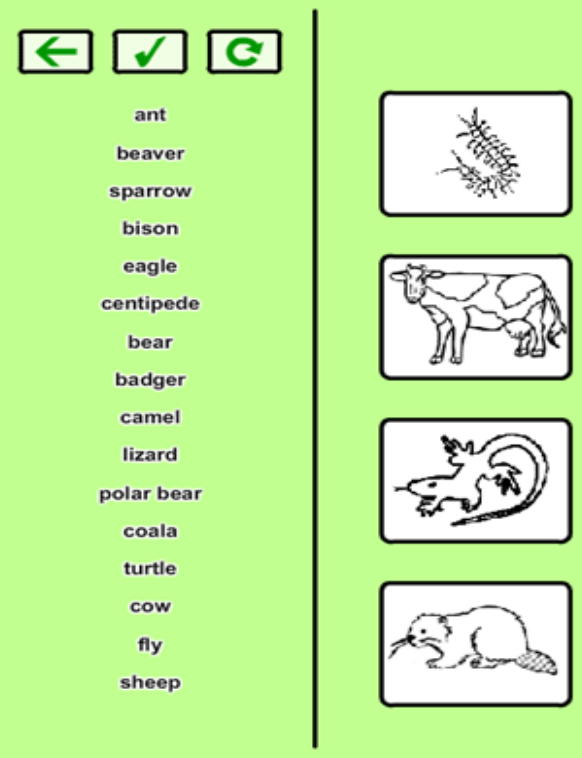

Húzd a szavakat a megfelelõ helyre!
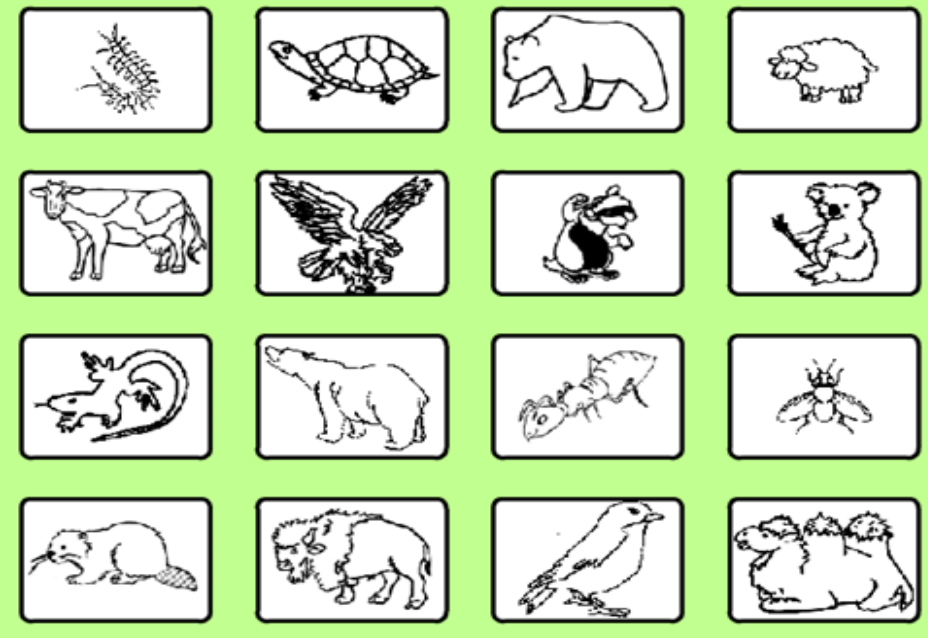

Figure 7: Matching game

Citation: Zsigmond HB, Soltész I, Blaske B, Horváth O, Csorba B, Anita S, (2018) Teaching Grammar with the Help of Computer-Based 


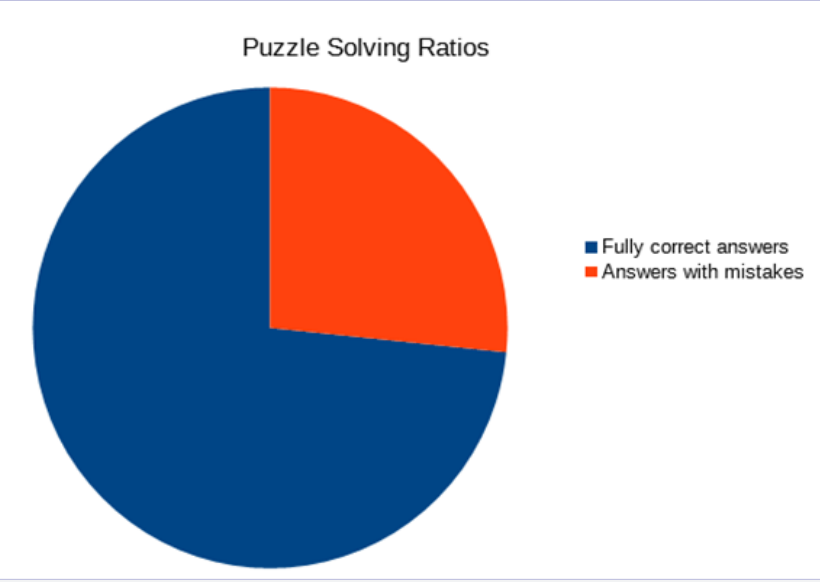

Figure 8: Ratio between perfect and imperfect solutions

Present Continuous. The last test had a mixed agenda, consisting of both tenses. The control group followed the coursebook it was using without any extra materials. The tests of the group members were done in accordance with the regular syllabus.

The final test of the trial group of mixed tenses was used as the basis of comparison between the groups. The test consisted of 18 items of translation with variations in difficulty. Four items were trick questions presenting Gerund forms and Stative Verbs. These topics were covered before with both groups separately, so there were no differentiation concerning the depth of the taught materials, just of the type of tasks they had to perform before writing the final test which was provided traditionally on paper.

\section{Results}

There was no significant difference between how well the students performed translations and sentence compositions. Typical mistakes of affixes and the missing forms of the verb 'to be' were constantly present.

The results of the tests considered as milestones are shown on Figure 9.

The average rate for the single tense test was: $72 \%$ for the Present Simple test, 75\% for the Present Continuous test and $66 \%$ for the mixed tenses test. Two conclusions could be made at this stage. Firstly somehow the continuous forms gained more emphasis in primary school by the teachers and they were cemented in the learning experience so much that many of the mistakes in the Present Simple test was due to the incorrect use of them. Secondly the students still have difficulty to correctly distinguish the different meanings of the sentences when they see them mixed and they have to translate them.

The result of the comparison between the trial and the control group is shown on Figure 10.

Although there is a difference in the member count of the two groups, the gap between the performances of the students is still very visible. Only 3 people from the control group managed to score over $60 \%$ and one of them only did it by a small margin. In the trial group 15 people did surpass and 3 of them reached almost maximum scores.
The difference of the average result between the trial and the control group is shown in Figure 11.

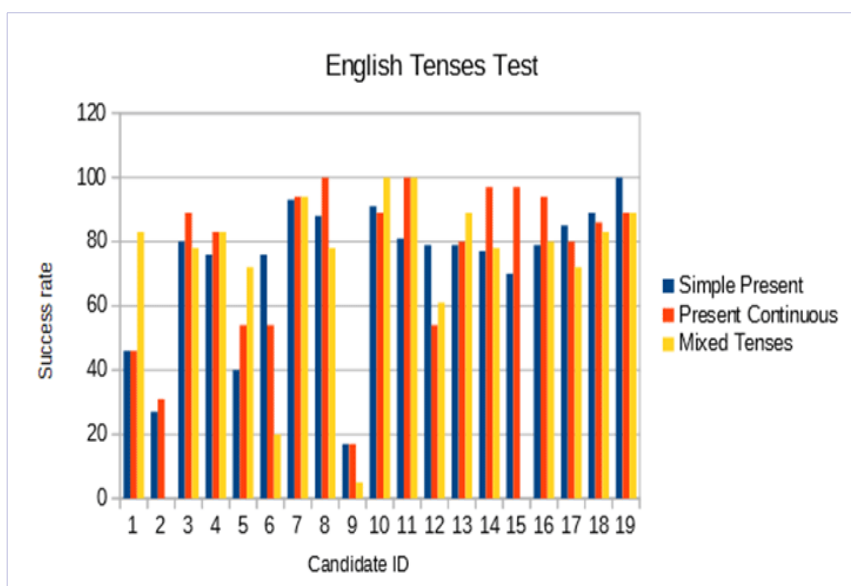

Figure 9: Results of the entire graded test in comparison with each other in percentages. Two students didn't attend the final testing occasion.

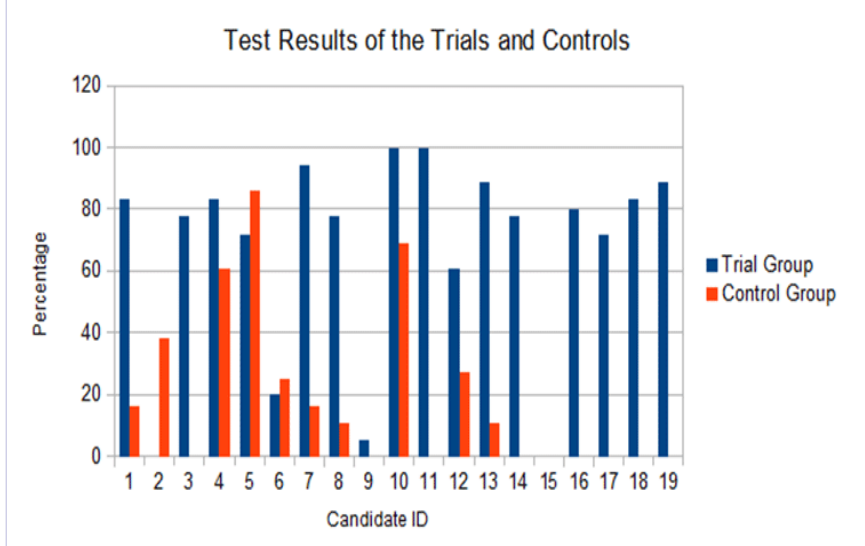

Figure 10: Shows the results of the final test of mixed tenses among the members of the trial and control group. The missing data presents missed testing occasions or member count difference.

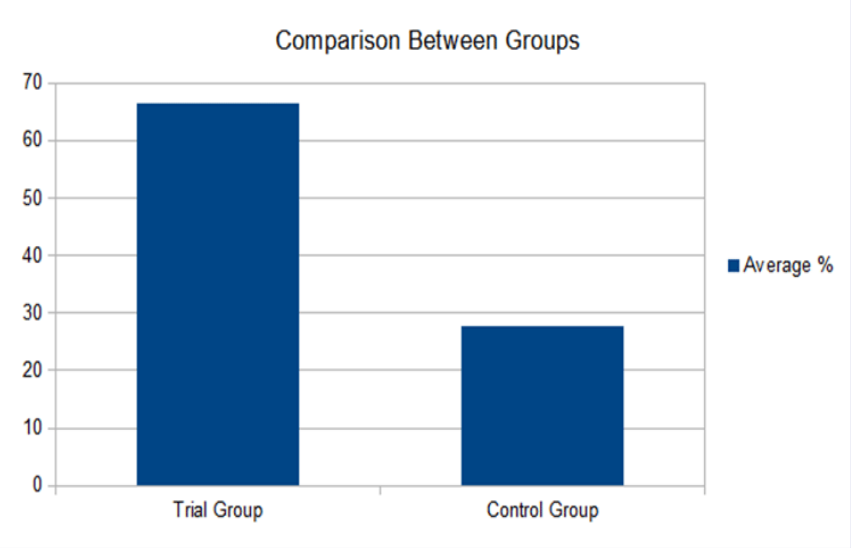

Figure 11:Overall difference between the groups in percentages

Based on the results, we can establish that it is very advisable to use the above-mentioned practising methods. Both approaches of using puzzles and sentence translation/formation should be 
used parallel with each other in order to make the students aware of the necessity of correct grammar forms but also add enjoyment to the process. Practice indeed makes perfect.

\section{Conclusion}

The main notion we could gain from our research is that teaching with methods that are more challenging for students is still a constant demand. Puzzle solving has a valid and useful place in education and could be used both for teaching grammar and vocabulary, but only if there are some linking exercises to it that put the puzzles in some reality- and task-based context. So far there seems to be convincing picture that there is a pattern of how to use puzzles in the right way and they seem to remain a colourful activity type to lighten the mood of a course. It is an interesting notion that students prefer grammatically more complex puzzles to simple vocabulary learning as long as the puzzles are enjoyable.

It is common knowledge that people tend to remember those things that could be linked with activities that are not boring, even when we are speaking of remembering dry materials. It is very rare still that puzzles would be used as proper testing methods, as they seem to be considered less academic, but they are ever increasingly used for practice and it is clear to see that they help develop learner autonomy. A more fertile ground is to observe how puzzles evolve from the technical aspect and that may be the key of how to use them more wisely in education.

\section{Future Research}

In the future we would like to develop the LGATE task sheets for all the verb tenses and thus research can go in different directions. The full length of the learning process will be three and half years long and the success rate will be measured by the factors of successful school-leaving exams with a better outcome than average and successful intermediate or advanced level language exams. We would also like to implement all of the puzzle types for all grammar topics.

\section{Acknowledgements}

The author would like to express his sincere thanks to all participating colleagues and students.

\section{References}

1. Albert D. The Competence Performance Distinction and It's Implications for teacher Education and Training. In S. Higuchi (Ed.), Comparative study on teacher education system between Austria and Japan for constructing a new conception of teacher training. 2008:187-206.

2. Han Ji-Sook. The role of metacognition in teaching geosciences. 2008.

3. Adedoja GO, Fakokunde JB. Effects of Computer-Based Instructional Puzzle on Students' Learning Outcomes and Retention in Social Studies. International Journal of Humanities and Social Science. 2015;5(11):181-187.

4. Peters PS, Ritchie RW. On the generative power of transformational grammars. Information Sciences. 1973;6:49-83.

5. Hardin LE. Problem solving concepts and theories. J Vet Med Educ. 2003;30(3):226-229.

6. Anderson JR. Cognitive psychology and its implications. 1980; San Francisco: Freeman.

7. Samida DK. Language learning strategies. Journal of Hokkaido Bunkyo University. 2004.

8. Alemi M, Daftarifard P. Pedagogical Innovations in Language Teaching Methodologies. Journal of Language Teaching and Research. 2010;1(6):765-770.

9. Danesi M. Puzzles in Language Teaching. Canadian Modern Language Review. 1979;35(2):269-277.

10. Bouteliaten A. The Effectiveness of Using Crossword Puzzles as a Teaching Strategy to Enhance Students' Knowledge of Vocabulary. 2010.

11. McDonald K. Teaching 12 vocabulary through logic puzzles. Estudios de lingüística inglesa aplicada. 2007;7:149-163.

12. Cuesta MR. A task-based approach to language teaching: the case for task-based grammar activities. Revista Alicantina de Estudios Ingleses. 1995;8:91-100.

13. Von Nimwegen C, Van Oostendorp H, Schijf H. Can more help be worse? The over-assisting interface. 2004.

14. Niall McCarthy. Two Thirds of Working-Age Europeans Know a Foreign Language. Statista.com. 2013.

15. What's wrong with Japanese education? Japan Today. 2012. Available from: https://japantoday.com/category/features/opinions/whatswrong-with-japanese-education

16. Horváth B Z. Duenna-An experimental language teaching application. SoftwareX. 2016. 